Review Article

\title{
Necessity and Significance of Meditation in Life
}

\author{
Siddappa Naragatti', Garima ${ }^{2}$, Divya Valecha ${ }^{3}$ \\ ${ }^{1}$ Yoga Therapist, ${ }^{2}$ Senior Research Fellow, Central Council for Research in Yoga and Naturopathy, New Delhi, India. \\ ${ }^{3}$ Medical Officer, Central Government Health Scheme, New Delhi, India. \\ DOI: https://doi.org/10.24321/2394.6547.202010
}

I $\quad \mathbf{N} \quad \mathbf{F} \quad \mathbf{O}$

\section{Corresponding Author:}

Siddappa Naragatti, Central Council for Research

in Yoga and Naturopathy, New Delhi, India.

E-mail Id:

siddappa.naragatti@gmail.com

Orcid Id:

https://orcid.org/0000-0001-8644-4160

How to cite this article:

Naragatti S, Garima, Valecha D. Necessity and Significance of Meditation in Life. Adv Res Ayur Yoga Unani Sidd Homeo 2020; 7(3\&4): 27-30.

Date of Submission: 2020-12-12

Date of Acceptance: 2020-12-30

\section{$\begin{array}{llllllll}\mathbf{A} & \mathbf{B} & \mathbf{S} & \mathbf{T} & \mathbf{R} & \mathbf{A} & \mathbf{C} & \mathbf{T}\end{array}$}

This review article focuses on necessity and importance of meditation in life. Modern hazardous lifestyle and unhealthy work style resulting from money-making mind and selfish nature is causing various ailments. Only meditation is the way for overcoming these illnesses and leading a happy healthy life in this universe. Traditional ways are the justified footprints. It is the time to look inside the self with awareness and attention; this would provide us our own reflection; it would guide us where to go, what to do in life and how to achieve the ultimate goal of life. Our ancient yogis have achieved that stage with the help of meditation. Hereunder the authors have tried to draw the outline of the meditation for the wellbeing of the human being.

Keywords: Meditation, Need, Significance and Life

\section{Introduction}

Nowadays, there is a craze for learning "Meditation" not only in India but also worldwide. Mainly, it forms a part of religious practices. In recent times, "Meditation" is being used for therapeutic purposes rather than as a spiritual practice. Other initial preparation is needed to be practised before one learns to execute meditation. It should be kept in mind that in the ladder of yogic practices, meditation resides in a higher position than other practices. Compiler of Astang Yoga, Maharshi Patanjali has evidently said about eight steps of Yoga "Yama Niyama Asana Pranayama Pratyahar Dharana Dhyana Samadhaya Asthah Angani." ${ }^{1}$ Therefore, one should develop a good foundation unto Dharana and then go for Dhyana. Meditation is called in Sanskrit as Dhyana. Further, it is stated in Vibhutipad "Tatra Pratyaya Eikatanata Dhyanam;"2 it means meditation is a continuous attention without any distraction that is one-pointedness. Another great authenticated yoga text is Gheranda Samhita in which Gherand Muni states three types of meditation. "Sthulam Jyotistatha Suksham Dhyanasya Threevidham viduhah," ${ }^{3}$ means, in meditation, there are three types, namely, gross, subtle and luminous. In Vashistha Samhita, we find, "dhyanamatmaswarupasya vedanam manasa bhavet tadev dwividham proktam sagunam nirgunamtatha." ${ }^{4}$ When man becomes stable in soul conscious state, he comes to know the two types of meditation which are Sagun and Nirgun. One more reference from Shrimad Bhagawadgita explains more about meditation in Chapter 6 that " $A$ mechanical meditative practice, controls the mind and senses and focuses concentration on the supreme soul." ${ }^{5}$

Meditation is a psychological mechanism that confines motivation input by directing attention to a single unchanging or recurring motivation. ${ }^{6}$ It is an experiential practice to modify the state of perception. Meditation can be used as a no cultic practice. ${ }^{7}$ It has been physiologically termed as "wakeful, hypo-metabolic state". ${ }^{8}$

Some types of meditation techniques which are accepted globally are transcendental meditation, Vipasana Meditation, Zen meditation, Om meditation, cyclic meditation, Brahma Kumaris Raj Yoga Meditation, etc. This article is written with a view to give an idea on the need and importance of meditation in life irrespective of any diversity in lifestyle or culture. ${ }^{9}$ 


\section{Aim of Meditation}

A yogi or practitioner regularly meditating upon his God/ Goddess with the control of mind gets everlasting peace.

\section{Objectives of Meditation}

- Reduction of stressful condition

- Improvement in concentration power

- Improvement in thinking

- Strengthening the immune system in the body

- Slowing down the biological ageing process

\section{Method}

All the yogic practices contribute to the building up of the meditative mood. Rather than introducing mechanical method of meditation, the participants be brought to "meditative mood" and left there for a comfortable length of time. According to one's capacity, one determines the time. ${ }^{10}$

The method of meditation is related to the biofeedback mechanism and relaxation methods. ${ }^{11}$ Therefore, the method of teaching meditation requires an atmosphere of harmony through pleasant voice and easy methods leading to a meditative mood. ${ }^{12}$

Stable, comfortable and straight sitting posture with head, neck and trunk in a natural vertical line, implying natural three bends in the spinal column, and regulated breathing facilitates the practice of meditation. ${ }^{13}$ It will be advantageous, if one sits in any meditative posture, out of which Padmasana is the best, else any comfortable ${ }^{14}$ sitting position would do.

\section{Steps}

- Hatha Yoga Pradipika requires practice in a small room, situated in a solitary place, being four cubits square, and free from stones, fire, water, disturbances of all kinds and in a country where justice is properly administered, where good people live, and food can be obtained easily and plentifully ${ }^{15}$

- Srimad Bhagavadgita says that one should sit in a clean place on one's seat prepared out of Kusha-grass, and then a dear skin and a clean cloth are be placed one over the other ${ }^{16}$

- The sitting place should neither be too high nor too low.

- After sitting on that seat, one should concentrate one's mind with the control of thinking faculty and also the senses to meditate ${ }^{17}$

- It is further suggested that one should sit keeping the head, neck and trunk straight and also steadily gazing at the tip of the nose without looking here and there ${ }^{18}$

- Thus, meditator being fearless, serene, firm in celibacy, then concentrates upon beloved God whom he likes most $^{19}$

\section{Do's in Meditation}

- $\quad$ Sit in a clean place on soft mat

- It should be neither too high nor too low

- Concentrate upon beloved God/ Goddess

- $\quad$ Sit with the head, neck and trunk straight

- Withdraw all the senses

- Have passive attitude

- Gaze steadily at the tip of the nose

- Bind the territory of Chitta Vikshepas, that is, psychophysiological disturbances ${ }^{20}$

- Further concentrate the mind with the control of thinking faculty. Thus, establish well unto concentration

\section{Don't in Meditation}

- Do not open the eyes throughout the activity for all sensory organs are the possible channels to get disturbances

- Do not shake or move your body position ${ }^{21}$

- Do not have doer attitude

\section{Advantages of Meditation}

Broadly speaking the effects can be seen on various psychophysiological levels.

- In meditation, one gets profound rest for the body and mind. The consumption of Oxygen can be lowered during 20-30 minutes of meditation to a degree, which can be reached after 6-7 hours of sleep ${ }^{22}$

- Heart rate decreases ${ }^{23}$

- Respiratory rate decreases ${ }^{24}$

- There is a shift towards parasympathetic dominance.25

- Lowering of anxiety is seen at that time ${ }^{26}$

- During meditation, EEG shows an altered-drowsy pattern with high alphas and occasional theta wave patterns as well as unusual pattern of swift from alpha to slower frequencies and then backs again ${ }^{27}$

- When practiced regularly, it appears that "meditation" alters behavior ${ }^{28}$

\section{Limitations in Meditation}

Meditation has its limitations. All people cannot practice meditation even for 20 to 30 minutes. Overdose of meditation for such persons can be dangerous. Release of certain emotions that is difficult to handle, may occur with prolonged meditation. Therefore, in Vipasana Meditation, there is a frequent brake in meditation class. Even in relatively stable people, probably it will be unwise to introduce prolonged sessions of meditation. To avoid such difficulties, meditation should be practiced in moderation. It would be beneficial to start the practice of meditation after some amount of practice with stretching like asanas, rhythmic breathing like Pranayama and relaxative technique like Shavasana. It is doubtful whether meditation can really be ever taught effectively to a person with an adverse 
psychiatric history. The theory of "the more the better" cannot be applied here.

\section{Research Findings}

Esteemed Swami Kuvalyanand and his associates in the past carried out very authentic research study. The result showed primary difference among three similar mental states. They were hypnotic state, drunken condition and meditative state, which apparently appear to be very similar to each other. ${ }^{29}$ This result indicates the insight conveyed in the sutra "Janma Aushadhi Mantra Tapah Samadhijah Siddhayah." ${ }^{\prime 30}$ It was observed that out of three conditions, rest two were aware of pricking sensation and sound, while a meditator was not. Gharote (1971) in his study found that the energy ${ }^{31}$ expenditure in a session of meditation for 45 minutes duration reduced significantly in a progressive way while it was increased soon after meditation session. In an X-ray experiment with barium meal, Bhole (1983) studied stomach tone in shape, ${ }^{32}$ size and mucosal pattern of the same during relaxation cum meditation for 5 minutes duration to overcome emotional disturbance.

In an another study conducted on experienced practitioners of Brahmakumari's Raja Yoga meditation, while participating in a functional magnetic resonance imaging study, the meditators were able to reach a deep meditative state (suggested by pulse rate and breath rate changes), while in the 'loud' scanner environment. ${ }^{33}$ The study showed significant activation in the primary visual cortex. Recently, it was found in a study by Naragatti, (2019), Brahmakumari's Raja Yoga meditation produces changes at the level of the mesencephalon-diencephalon. ${ }^{34}$ The study was conducted on healthy volunteers and showed a significant improvement in yoga group on all the four domains, compared to control group. Meditation practice of regular Brahmakumari's Raja Yoga meditation technique helps in improving the quality of life. ${ }^{35}$

\section{Conclusion}

Recent studies have suggested that meditation relaxes the body and mind and improves life state. The study provides ample evidence that the one who meditates regularly would have a magnetic and charming personality. Those who see the meditator are impressed by his/ her extraordinary traits such as sweet voice, powerful speech, shiny eyes, glow, outstanding behavior and divine nature. Real peace and joy can be attained by extinguishing past impressions and desires by means of meditation.

\section{Conflict of Interest: None}

\section{References}

1. Pantanjali Yoga Sutra //2:29//.

2. Patanjali Yoga Sutra $/ / 3: 2 / /$.

3. Gheranda Samhita //6:1//.
4. Vashistha Samhita //4:19//, //4:20//, //4:21// and $/ / 4: 31 / /$.

5. Shrimad Bhagawadgita Chapter 6 .

6. Bigliassi M. Psychological and Cardiovascular Effects of Meditation and Yoga. Brain and Heart Dynamics 2020; 913-920.

7. Jirakittayakorn $\mathrm{N}$, Wongsawat $\mathrm{Y}$. Brain responses to a 6-Hz binaural beat: effects on general theta rhythm and frontal midline theta activity. Frontiers in neuroscience 2017; 11, 365.

8. Cahn BR, Polich J. Meditation states and traits: EEG, ERP, and neuroimaging studies. Psychological bulletin 2006; 132(2): 180.

9. Ramakrishnan P, Dias A, Rane A, Shukla A, Lakshmi S, Ansari BKM et al. Perspectives of Indian traditional and allopathic professionals on religion/spirituality and its role in medicine: basis for developing an integrative medicine program. Journal of Religion and Health 2014; 53(4): 1161-1175.

10. Walach H. Towards an epistemology of inner experience. In Meditation-Neuroscientific Approaches and Philosophical Implications (pp. 7-22). Springer, Cham. 2014.

11. Aggarwal A. Hypothalamo-Pituitary-Adrenal axis and Brain during Stress, Yoga and Meditation. International Journal of Health and Clinical Research 2020; 3(9): 96-103.

12. Tang YY, Hölzel BK, Posner MI. The neuroscience of mindfulness meditation. Nature Reviews Neuroscience 2015; 16(4): 213-225.

13. Newcombe S, O'Brien-Kop K. (Eds.). Routledge Handbook of Yoga and Meditation Studies. Routledge. 2020.

14. Patanjali Yoga Sutra //2:46//.

15. Hatha Yoga Pradipika //1:12//.

16. Srimad Bhagwadgita //6:11//.

17. Srimad Bhagwadgita $/ / 6: 12 / /$.

18. Srimad Bhagwadgita $/ / 6: 13 / /$.

19. Srimad Bhagwadgita //6:14//.

20. Kang C, Whittingham K. Mindfulness: A dialogue between Buddhism and clinical psychology. Mindfulness 2010; 1(3): 161-173.

21. Abdul Wahab Pathath. Meditation: Techniques and Benefits. Int J Curr Res Med Sci 2017; 3(6): 162-168. DOI: http://dx.doi.org/10.22192/ijcrms.2017.03.06.021.

22. Jirakittayakorn $\mathrm{N}$, Wongsawat $\mathrm{Y}$. Brain responses to a 6-Hz binaural beat: effects on general theta rhythm and frontal midline theta activity. Frontiers in neuroscience 2017; 11: 365.

23. Khalsa SS, Rudrauf D, Davidson RJ, Tranel D. The effect of meditation on regulation of internal body states. Frontiers in psychology 2015; 6: 924.

24. Goldstein E, Topitzes J, Brown RL, Barrett B. Mediational 
pathways of meditation and exercise on mental health and perceived stress: A randomized controlled trial. Journal of health psychology 2020; 25(12): 1816-1830.

25. Samuel G. Mindfulness within the full range of Buddhist and Asian meditative practices. In Handbook of Mindfulness (pp. 47-62). Springer, Cham. 2016.

26. Goyal M, Singh S, Sibinga EM, Gould NF, RowlandSeymour A, Sharma R et al. Meditation programs for psychological stress and well-being: a systematic review and meta-analysis. JAMA internal medicine 2014; 174(3): 357-368.

27. Jadhav N, Manthalkar R, Joshi Y. Effect of meditation on emotional response: An EEG-based study. Biomedical Signal Processing and Control 2017; 34: 101-113.

28. Nathawat SS, Gupta M. Effect of Meditative Techniques and Relaxation on Psychological Well-being. Amity Journal of Applied Psychology 2011; 2(1).

29. Swami K. "Some physiological aspects of meditation poses" Yoga Mimamsa, Lonavala Kaivalyadhama, 1928; 245-250.

30. Patanjali Yoga Sutra //4:1//.

31. Gharote ML. Energy Expenditure during Deep Meditative State. Yoga Mimamsa, Lonavala Kaivalyadhama 1971; 14(1\&2): 57-62.

32. Bhole MV. Gastric tone as influenced by mental tate and meditation. Yoga Mimamsa 1983; 22(1\&2): 54-58.

33. Naragatti S, Hiregoudar NK. Brahma Kumaris Sahaj Raj-Yoga Meditation - As a Tool to Manage Various Levels of Stress. J Adv Res Ayur Yoga Unani Sidd Homeo 2019; 6(1\&2): 1-9.

34. Sharma K, Achermann P, Panwar B, Sahoo S, Angarai R, Pascual-Marqui RD et al. Brain-electric activity during eyes open Brahma Kumaris Rajayoga meditation. 2020.

35. Naragatti S, Acharya DIN, Rastogi DR. Effects of Meditation on Health. International Journal of Medical and Biomedical Studies 2019; 3(1). From: DOI: https:// doi.org/10.32553/ijmbs.v3i1.82. 